\title{
Resolution of Alcohol Racemate by Oil
}

\author{
Adi Wolfson*, Nadia Komyagina, Christina Dlugy, Janine Blumenfeld \\ Green Processes Centre, Chemical Engineering Department, Sami Shamoon College of Engineering, \\ Bialik/Basel Sts. Beer-Sheva, Israel \\ E-mail: adiw@sce.ac.il
}

Received January 7, 2011; revised January 28, 2011; accepted January 30, 2011

\begin{abstract}
Vegetable oil was successfully used as solvent and acyl donor in the kinetic resolution of several secondary alcohol racemates yielding high enantioselectivities. Using vegetable oil as solvent and acyl donor allowed easy separation of the pure alcohol enantiomer by extraction with methanol, by distillation under reduced pressure, or by column chromatography.
\end{abstract}

Keywords: Oil, Kinetic Resolution, Lipase, Separation

\section{Introduction}

Optically pure chiral compounds are important building blocks in the production of fine chemicals for pharmaceuticals, agrochemicals, and food ingredients [1,2]. Pure enantiomers can be produced by using the "chiral pool" of readily available natural compounds as starting materials, by resolving a racemic mixture, or by generating asymmetry through asymmetric synthesis [3,4].

As starting materials, racemates can be obtained from natural sources or by 'classical' chemical synthesis [1,2]. Since enantiomers exhibit different chemical activities in a chiral environment, when a racemic mixture reacts with a chiral (bio- or chemo-) catalyst, the different conversion rates of the two enantiomers lead to the enrichment of the less active enantiomer in the mixture. Other methods of enriching enantiomers are preferential crystallization and separation by chiral HPLC and chiral membrane. However, these methodologies typically return low theoretical yields (maximum 50\%) of the pure product.

Chiral alcohols are useful intermediates and auxiliaries in the production of various fine chemicals $[5,6]$. Pure alcohol enantiomers can be produced by asymmetric hydrogenation or transfer hydrogenation of the corresponding carbonyl compounds using bio- and chemocatalysts [7-10] or by resolution of alcohol racemate $[1,2]$. Lipase catalyzed kinetic resolution of alcohol racemate is the oldest and most commonly used method of obtaining pure alcohol enantiomers [11-15]. Several other methods-such as direct esterification using carboxylic acid, transesterification using an ester as acyl donor, and acylation by acyl chloride, anhydride, or vinyl alkanoates-which differ in the type of acyl donor, can be used for the resolution.

While water is the solvent of choice for most biocatalysis synthesis reactions, it cannot be used for alcohol resolution, as it directs the reverse reaction, ester hydrolysis. Yet, as enzymes require no more than a monolayer or so of water around them to preserve their conformation and thus their activity, it can also be used in an organic medium. It was found that the most hydrophobic solvents were the best for maintaining active enzymes mainly since the non-polar solvent cannot strip the water from the protein and as such, does not change its native structure [15]. The kinetic resolution of alcohols in an organic medium was previously reported with several free and immobilized lipases. In those studies, Candida antarctica lipase B (CAL-B) and its supported analogues were mostly used [11-15].

As is typical of many organic reactions, in the kinetic resolution of alcohols, the choice of the solvent is critical. Besides activity and enantioselectivity, solvent selection should also consider environmental aspects and product separation procedure. We recently showed that using glycerol triacetate (triacetin) as both solvent and acyl donor in the kinetic resolution of alcohol resulted in high conversions and enantioselectivities, and that the product was easily separated by simple extraction with diethyl ether [15]. Not only is triacetin environmentally friendly and non-toxic, using it as acyl donor yielded by-products that remained in the reaction mixture, and thus, only the converted and unconverted enantiomers were separated. 
In this paper we report on our study about the kinetic resolution of several secondary alcohol racemates with immobilized C. antarctica lipase B (CAL-B) in vegetable oil (Figure 1). The oil was used not only as solvent, but also as acyl donor, yielding pure (S)-alcohol enantiomer and ester of (R)-alcohol enantiomer and fatty acid. The effects of oil source and reaction condition on resolution activity and enantioselectivity were studied together with separation techniques for (S)-alcohol enantiomer purification.

\section{Experimental}

All chemicals were purchased from Aldrich, except some of the vegetable oils, which were bought at a supermarket.

\subsection{Kinetic Resolution}

In a typical reaction, $2.3 \mathrm{mmol}$ of alcohol racemate were added to $5 \mathrm{~mL}$ vegetable oil together with $0.043 \mathrm{~g}$ of $\mathrm{C}$. antarctica lipase B immobilized on acrylic resin. The reaction mixture was heated in an oil bath to the required temperature $\left(80^{\circ} \mathrm{C}\right)$ and mixed with stirrer for $5 \mathrm{~h}$. At the end of the reaction, the reaction mixture was cooled and analyzed by TLC to determine alcohol conversion. In addition, the products were extracted with $2 \mathrm{~mL}$ of methanol for GC-analysis.

For the analytical procedure, the reaction mixture was analyzed by GC using an Astec Chiraldex G-TA chiral column $(30 \mathrm{~m} \times 0.25 \mathrm{~mm}, 0.25 \mu \mathrm{m}$ thickness $)$ to determine the reaction conversion and the enantiomeric excess. The injector temperature was $220^{\circ} \mathrm{C}$, and the FID detector temperature was $250^{\circ} \mathrm{C}$. The temperature program initialized at $80^{\circ} \mathrm{C}$ for $5 \mathrm{~min}$ and then increased up to $180^{\circ} \mathrm{C}$ at a rate of $10^{\circ} \mathrm{C} / \mathrm{min}$.

\subsection{Alcohol Separation}

Pure alcohol enantiomer separation was tested by several techniques. First, kinetic resolution of 2-octanol was performed by adding $0.305 \mathrm{~g}$ immobilized CAL-B and $16.1 \mathrm{mmol} 2$-octanol to $35 \mathrm{~mL}$ canola oil (purchased from Aldrich). Then the reaction mixture was mixed in an oil bath at $80^{\circ} \mathrm{C}$ for $5 \mathrm{~h}$, and the immobilized lipase was filtrated from the reaction mixture at the end of the reaction.

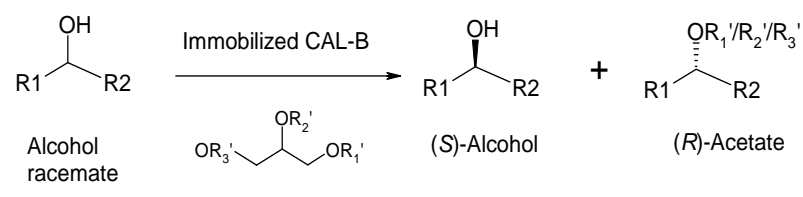

Figure 1. Kinetic resolution of a secondary alcohol racemate in oil.
Two methanol-based alcohol enantiomer extraction procedures were used. In the first procedure, $150 \mathrm{~mL}$ of methanol were added to the reaction mixture in a $250 \mathrm{~mL}$ Erlenmeyer flask and mixed for $30 \mathrm{~min}$, after which phase separation was performed. The methanol was then evaporated under reduced pressure in a Rotavapor. The second procedure entailed a six-step extraction done using $25 \mathrm{~mL}$ of methanol for each step. The extracts from all the steps were then joined and evaporated under reduced pressure in a Rotavapor. For both of the procedures, the resultant crude was weighed and analyzed by TLC to determine oil and methyl ester contents and by $\mathrm{GC}$ to detect the total amount of (S)-2-octanol in the crude. The extraction yield was calculated by dividing the weight of the crude by half of the weight of the 2-octanol, and the purity was calculated by dividing the total amount of (S)-2-octanol by half the weight of the 2-octanol.

Distillation of (S)-2-octanol from the reaction mixture was tested under reduced pressure at $120^{\circ} \mathrm{C}$ or $90^{\circ} \mathrm{C}$. At the end of each process, the distillate was weighed and analyzed by TLC and GC, and the total alcohol yield and content were calculated as detailed above.

Column chromatography was run in a glass column measuring $1 \mathrm{~m}$ long by $6 \mathrm{~cm}$ in diameter. A portion of $5 \mathrm{~g}$ glass wood was fixed at the bottom of the column, and above it was a $0.5 \mathrm{~cm}$ layer of sand. The column was filled with silica gel as the stationery phase while dichloromethane was used as the mobile phase. The elution was collected at the end of the column and analyzed by TLC to determine when the oil and the methyl ester exited the column relative to the alcohol enantiomer (the oil and the methyl ester were eluted out before the alcohol). The fraction of (S)-2-octanol was collected, and dichloromethane was evaporated under reduced pressure in a Rotavapor. At the end of the process, the crude was weighed and analyzed by TLC and GC, and the total alcohol yield and content were calculated as detailed above.

\section{Results and Discussion}

The main motivation to perform the kinetic resolution of alcohol racemate by oil was to test an alternative to the toxic and expensive petroleum based organic solvents usually employed for this purpose. Moreover, in addition to its function as a solvent, the oil also acted as resolution agent, which resulted in two different enantiomers, an alcohol and an ester of alcohol, and a fatty acid. As the two different enantiomers have different molecular structure and thus have different polarities, solubilities, and boiling points in oil, the pure alcohol enantiomer can be separated using techniques in which there is no need to first separate the alcohol and ester enantiomers from the reaction mixture before separating between them. 
The investigation began by testing the performance of immobilized CAL-B in the kinetic resolution of racemic mixtures of 2-octanol as a representative compound using several different types of oil (e.g., sunflower, corn, soybean, and canola oils) that were bought from a supermarket and some canola oil purchased from Aldrich (Table 1). The reactions were run at $80^{\circ} \mathrm{C}$ for $5 \mathrm{~h}$ in two scales $(2.3 \mathrm{mmol} 2$-alcohol in $5 \mathrm{~mL}$ oil and $16.1 \mathrm{mmol}$ 2-alcohol in $35 \mathrm{~mL}$ oil). In all cases, full alcohol conversion was achieved.

As illustrated in Table 1, in the kinetic resolution of 2-octanol, the source of the oil slightly affected the enantiomeric excess (\%ee) value of the resultant alcohol enantiomer (entries 1-4), and the highest \%ee was observed in canola oil. Cooking oil comprises mainly triglycerides, but it also contains other chemicals, such as odors and flavors, as well as antioxidants [17]. Therefore, from all oil types, alcohol extraction also tuned up some unrecognized organic compounds, which were also detected when canola oil was bought from Aldrich. Replacing 2octanol by 2-butanol or 2-phenylethanol resulted in similar conversions and enantiomeric excess values (entries 8-11). Performing the resolution with larger amounts of secondary alcohol, oil, and enzyme yielded the same results (entries 7 and 9).

Tests of the effect of reaction temperature on reaction progress over time showed that the enantioselectivity of 2-octanol, which also depended on the reaction conversion, increased with both the reaction temperature and time, as expected. At temperatures below $60^{\circ} \mathrm{C}$, the reaction progressed slowly with time, while at temperatures above $60^{\circ} \mathrm{C}$, the reaction reached full conversion and \%ee after one hour (Figure 2). This effect may be attributable to an energy barrier that can be overcome faster at higher temperatures and to the decrease, as the temperature increased, in the viscosity of oil, which served to increase both mass and heat transfer.

The separation of pure alcohol enantiomer was tested by several techniques after running the kinetic resolution

Table 1. Lipase catalyzed kinetic resolution of 2 -alcohol ${ }^{\mathrm{a}}$.

\begin{tabular}{cccc}
\hline Entry & Oil Source & Alcohol type & $\begin{array}{c}\text { ee, (S) } \\
\text {-alcohol (\%) }\end{array}$ \\
\hline 1 & Sunflower & 2-Octanol & 95 \\
2 & Corn & 2-Octanol & 97 \\
3 & Soybean & 2-Octanol & 93 \\
4 & Canola & 2-Octanol & 98 \\
5 & Canola (Aldrich) & 2-Octanol & 98 \\
$6^{\text {b }}$ & Canola (Aldrich) & 2-Octanol & 98 \\
7 & Canola (Aldrich) & 2-Butanol & 98 \\
8 & Canola (Aldrich) & 2-Phenylethanol & 99 \\
$9^{\text {b }}$ & Canola (Aldrich) & 2-Phenylethanol & 99 \\
\hline
\end{tabular}

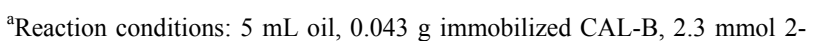
alcohol, $80^{\circ} \mathrm{C}, 5 \mathrm{~h}$; ${ }^{\mathrm{b}}$ Reaction conditions: $35 \mathrm{~mL}$ oil, $0.305 \mathrm{~g}$ immobilized CAL-B, $16.1 \mathrm{mmol}$ 2-alcohol, $80^{\circ} \mathrm{C}, 5 \mathrm{~h}$.

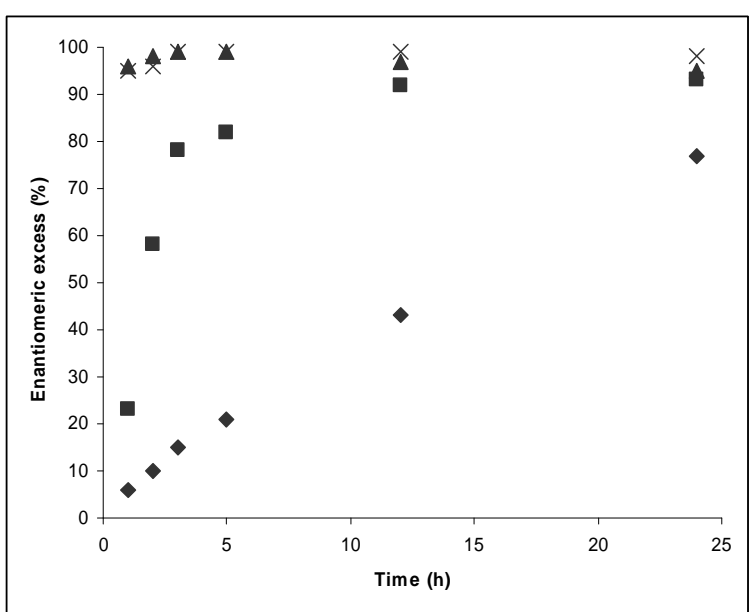

Figure 2. Reaction progress over time at different temperatures. Reaction conditions: $35 \mathrm{~mL}$ oil, $0.305 \mathrm{~g}$ immobilized lipase CAL-B, 16.1 mmol 2-octanol. (४) $25^{\circ} \mathrm{C}$; (घ) $40^{\circ} \mathrm{C}$; (×) $60^{\circ} \mathrm{C}$; $(\Delta) 80^{\circ} \mathrm{C}$.

of 2-octanol according to the procedure of Table 1 (entry 6) and filtration of the immobilized lipase from the reaction mixture at the end of the reaction (Table 2). First, extraction of the product was examined. As oil is a hydrophobic organic liquid, several hydrophilic extraction solvents may be considered. Water, an oil immiscible solvent that forms a biphasic system with oil but that poorly dissolves most secondary alcohols, cannot be employed for the extraction. On the other hand, polar solvents like acetonitrile and DMSO were dissolved in the oil phase. It was found that methanol and vegetable oil have a low mutual solubility, while methanol efficiently dissolved secondary alcohols, identifying it as the most suitable solvent for the extraction.

The extraction of (S)-2-octanol from the reaction mixture by methanol was tested using two procedures. In the first procedure, $150 \mathrm{~mL}$ of methanol were added to the reaction mixture in a $250 \mathrm{~mL}$ Erlenmeyer flask and mixed for 30 min followed by phase separation (Table 2, entry 1). Then the methanol was evaporated under reduced pressure in a Rotavapor, and the resultant crude was weighed and analyzed in TLC and GC. It was found that the overall yield, based on (S)-2-octanol, was above $100 \%$, as the extraction mixture also contained some oil and small amounts of uncharacterized organic molecules. Based on GC analysis, the percentage of (S)-2-octanol in the extraction mixture was $89.7 \%$, which implies that all the alcohol was extracted from the reaction mixture. Performing the extraction in six extraction steps using $25 \mathrm{~mL}$ of methanol in each step resulted in a lower extraction yield and a slightly higher purity of the crude aftermethanol evaporation, mainly as the oil content in the extract decreased (entry 2). 
Table 2. Separation of (S)-2-octanol from oil ${ }^{\mathrm{a}}$.

\begin{tabular}{clcc}
\hline Entry & \multicolumn{1}{c}{ Separation technique } & $\begin{array}{c}\text { Total } \\
\text { yield }\end{array}$ & $\begin{array}{c}\text { Alcohol } \\
\text { purity (\%) }\end{array}$ \\
\hline 1 & $\begin{array}{l}\text { Extraction-one step } \\
(150 \mathrm{~mL} \text { methanol })\end{array}$ & 115 & 89.7 \\
2 & $\begin{array}{l}\text { Extraction-six step } \\
(6 \times 25 \mathrm{~mL} \text { methanol })\end{array}$ & 109 & 92.4 \\
3 & Distillation-120 ${ }^{\circ} \mathrm{C}$ & 150 & 67.7 \\
4 & Distillation-90 $0^{\circ} \mathrm{C}$ & 89 & 95.2 \\
5 & Column-dichloromethane & 72 & 99 \\
\hline
\end{tabular}

${ }^{a}$ Reaction conditions: $35 \mathrm{~mL}$ oil, $0.305 \mathrm{~g}$ immobilized CAL-B, $16.1 \mathrm{mmol}$ 2-octanol, $80^{\circ} \mathrm{C}, 5 \mathrm{~h}$; ${ }^{\mathrm{b}}$ Based on 2-octanol.

Distillation of (S)-2-octanol from the reaction mixture was also tested (Table 2, entries 3 and 4). Because the boiling point of 2-octanol is relatively high, the distillations were done under reduced pressure. Performing the distillation at a high temperature of $120^{\circ} \mathrm{C}$ (entry 3) resulted in large amounts of various organic compounds, probably from the destruction of the oil molecules, and therefore, the total yield was above $100 \%$. Lowering the distillation temperature to $90^{\circ} \mathrm{C}$ produced lower yield of (S)-2-octanol and a low organic compounds content.

Finally, column chromatography was also used for the separation of the alcohol from the oil and the ester (Table 2 , entry 5 ). Several solvents, such as ethyl acetate, petroleum ether, or dichloromethane, alone or in mixtures and with methanol, were tested. It was found that using dichloromethane produced the best difference between the retention factors (Rf) of the oil and ester mixture and of (S)-2-octanol. Ethyl acetate had high elution strength, which resulted in a high level of transport of all materials through the column. When using petroleum ether, their transport through the column was very slow. Performing the column separation with dichloromethane yielded $72 \%$ pure (S)-2-octanol (entry 5 ).

\section{Conclusions}

Vegetable oil functions well as solvent and acyl donor in the kinetic resolution of secondary alcohol racemates. Various oil types can be used for the transesterification step, yielding high enantioselectivities. Increasing either reaction temperature or time increased the reaction rate. Separation of the pure alcohol enantiomer from the reaction mixture at the end of the reaction can be done by extraction with methanol, distillation under reduced pressure, or by column chromatography.

\section{References}

[1] R. A. Sheldon, "Chirotechnology: Industrial Synthesis of
Optically Active Compounds," Marcel Dekker, New York, 1993.

[2] A. N. Collins, G. Sheldarke and J. Crosby, "Chirality in Industry: The Commercial Manufacture and Application of Optically Active Compounds," John Wiley, New York, 1995.

[3] A. Baiker, "Progress in Asymmetric Heterogeneous Catalysis: Design of Novel Chirally Modified Platinum Metal Catalysts," Journal of Molecular Catalysis A: Chemical, Vol. 115, No. 3, 1997, pp. 473-493. doi:10.1016/S1381-1169(96)00352-4

[4] E. Santaniello, P. Ferrabosc, P. Grisenti and A. Manzocchi, "The Biocatalytic Approach to the Preparation of Enantiomerically Pure Chiral Building Blocks," Chemical Reviews, Vol. 92, No. 5, 1992, pp. 1071-1140. doi: $10.1021 / \mathrm{cr} 00013 \mathrm{a} 016$

[5] D. M. Tsachen, L. M. Fuentes J. E. Lynch, W. L. Laswell, R. P. Volante and I. Shinkai, "An Efficient Synthesis of 4-benzoyloxyazetidinone: An Important Carbapenem Intermediate," Tetrahedron Letters, Vol. 29, No. 23, 1988, pp. 2779-2782.

[6] K. Mori, "Synthesis of Optically Active Pheromones," Tetrahedron, Vol. 45, No. 11, 1989, pp. 3233-3298. doi:10.1016/S0040-4020(01)81007-3

[7] C. Dhenaut, I. Ledoux, I. D. W. Samuel, J. Zyss, M. Bourgault and H. Le Bozec, "Chiral Metal Complexes with Large Octupolar Optical Nonlinearities," Nature, Vol. 374, 1995, pp. 339-342. doi:10.1038/374339a0

[8] L. Poppe and L. Novak, "Selective Biocatalysis," VCH, Weinheim, 1992.

[9] L. H. Pignolet, "Homogeneous Catalysis with Metal Phosphine Complexes," Plenume Press, New York, 1983.

[10] R. Noyori, "Asymmetric Catalysis in Organic Synthesis," John Wiley, New York, 1994.

[11] E. E. Jacobsen, L. S. Andresen and T. Anthonsen, "Immobilization Does Not Influence the Enantioselectivity of CAL-B Catalyzed Kinetic Resolution of Secondary Slcohols," Tetrahedron: Asymmetry, Vol. 16, No. 4, 2005, pp. 847-850. doi:10.1016/j.tetasy.2004.11.081

[12] E. E. Jacobsen, E. W. van Hellemond, A. R. Moen, L. C. V. Prado and T. Anthonsen, "Enhanced Selectivity in Novozym 435 Catalyzed Kinetic Resolution of Secondary Alcohols and Butanoates Caused by the (R)-alcohols," Tetrahedron Letters, Vol. 44, No. 46, 2003, pp. 8453-8455. doi:10.1016/j.tetlet.2003.09.105

[13] N. Kim, S. B. Ko, M. S. Kwon, M. J. Kim and J. Park, "Air-Stable Racemization Catalyst for Dynamic Kinetic Resolution of Secondary Alcohols at Room Temperature," Organic Letters, Vol. 7, No. 20, 2005, pp. 4523-4526. doi:10.1021/o1051889x

[14] B. Martin-Matute, E. Michaela, K. Bogár, F. B. Kaynak and J. E. Bäckvall, "Combined Ruthenium(II) and Lipase Catalysis for Efficient Dynamic Kinetic Resolution of Secondary Alcohols. Insight into the Racemization Mechanism," Journal of the American Chemical Society, Vol. 127, No. 24, 2005, pp. 8817-8825.

doi:10.1021/ja051576x 
[15] C. Dlugy and A. Wolfson, "Lipase Catalyse Glycerolysis for Kinetic Resolution of Racemates," Bioprocess and Biosystems Engineering, Vol. 30, No. 5, 2006, pp. 327-330. doi:10.1007/s00449-007-0128-x

[16] A. Ballesteros, U. Bornscheuer, A. Capewell, D. Combes, J. S. Condoret and K. Koenig, "Review Article Enzymes in Non-Conventional Phases," Biocatalysis and Biotransformation, Vol. 13, No. 1, 1995, pp. 1-42. doi: $10.3109 / 10242429509040103$

[17] E. R. Sherwin, "Antioxidants for Vegetable Oils," Journal of the American Oil Chemists' Society, Vol. 53, No. 6, 1976, pp. 430-436. doi:10.1007/BF02605739 